\title{
Conflicto y causa mapuche en 2020: Una narrativa desde la escucha social
}

\author{
Mapuche cause and conflict in 2020: A Social Listening Narrative \\ Patricio Durán, Tomas Lawrence, Catalina Rolle \\ Fundación Interpreta, info@interpreta.org
}

\section{Historia editorial Resumen}

Recibido: 22/10/2021

Primera revisión:

$05 / 11 / 2021$

Aceptado: 01/12/2021

Publicado: 10/12/2021

\section{Palabras clave}

Mapuche, Escucha

Social, Araucanía,

Wallmapu, Escaños

Reservados, Camilo

Catrillanca, Alejandro

Treuquil, Víctor Pérez
El presente capítulo analiza los diversos hechos destacados en el año 2020 mapuche desde una perspectiva de escucha social. Tras recopilar más de tres millones y medio de menciones, se construyó una narrativa con datos y aportes obtenidos desde el mundo digital, para entregar una mirada distinta respecto a un año que estuvo fuertemente marcado por enfrentamientos entre el pueblo mapuche y el estado chileno, en medio del contexto de una pandemia y del inicio de un proceso constituyente.

\section{Abstract}

\section{Keywords}

Mapuche, Social Listening, Araucanía, Wallmapu, Reserved Seats, Camilo Catrillanca, Alejandro

Treuquil, Victor Pérez
The present chapter analyses the various facts that highlighted the mapuchean 2020 from a social listening perspective. After compiling more than three and a half million publications, we built a data-driven narrative with insights obtained from the digital world, to offer a different outlook regarding a year that was marked by confrontations between the mapuche people and the Chilean state during a pandemic and the beginning of a constituent process. 


\section{Introducción}

La escucha social o social listening es un proceso de monitoreo de Twitter y otras fuentes de información pública en internet, donde a través de una query o consulta a nuestro sistema se recopilan todos los datos disponibles respecto a un tema en particular. Actualmente tenemos acceso a más de 100 millones de páginas web, foros y portales de noticias, además del 100\% de perfiles públicos de Twitter. Para esta investigación, se aplicó el proceso de escucha social diseñado por la Fundación Interpreta para trackear todas las palabras clave ligadas a los mapuches, a su causa política y a su contexto en Chile. Con la proliferación de las redes sociales, el Social Listening y los monitoreos de redes sociales se han convertido en herramienta fundamental para entender problemáticas sociales complejas, como es la relación entre el Estado chileno y el pueblo mapuche. Así, el objetivo es poder entregar una cronología desde el punto de vista del mundo digital de lo que fue el 2020 para las comunidades mapuche en el marco de la pandemia y del plebiscito.

A lo largo de todo el año se recopilaron 3.591 .136 menciones desde Twitter, provenientes de 299.026 autores originales; 6.169 menciones de 40 medios de comunicación seleccionados en Twitter, además de 46.686 publicaciones en prensa, blogs y foros de internet. Para extraer información específica de estos datos se realizaron diferentes procesos de segmentación, lo que nos permitió categorizar la data para profundizar en los diferentes hallazgos que fuimos encontrando. El objetivo del presente capítulo no es simplemente entregar información cuantitativa acerca de las conversaciones en torno al Pueblo Mapuche en redes sociales, sino también contar -a través de los datos- el curso histórico respectivo a lo largo del 2020 desde las contrapuestas narrativas que nos fue posible encontrar en la web. 


\section{Un inicio de año tumultuoso}

A solo días de haber empezado el 2020, el 8 de enero el Tribunal Oral en Lo Penal de Temuco declaró culpable al comunero mapuche, Daniel Canio Tralcal, por los delitos de incendios a camiones y amenazas con armas de fuego a Carabineros. Los hechos habrían ocurrido dos años antes, en el fundo Oyama, propiedad de la Forestal Arauco del grupo Angelini.

Una vez más el gobierno fue partícipe del proceso judicial invocando la Ley Antiterrorista, la cual ha sido utilizada casi exclusivamente en el contexto del conflicto entre el Estado de Chile y el Pueblo Mapuche. Esto, aun cuando las cifras del Ministerio Público demuestran que las personas que han sido imputadas por delitos de terrorismo entre 2001 y 2016 fueron 127, de las cuales solo nueve de ellas resultaron fueron condenadas. Cabe destacar que, de ese número, ocho causas fueron dejadas sin efecto por sentencia de la Corte Interamericana de Derechos Humanos (CIDH) (Cortés, 2019). Al día siguiente de la sentencia del Tribunal, el 9 de enero, la Comisión de Ética contra la Tortura publicó un comunicado en el cual señalaron que el veredicto demostraba el carácter desproporcionado de la Justicia Chilena en los casos que involucraban a comuneros mapuche, y que la Ley Antiterrorista continuaba vulnerando los derechos de la justa defensa. Un ejemplo de esto es el uso de testigos anónimos, constituyéndose esta acción como un obstáculo a la hora de la búsqueda de equidad de las condenas que se dictan bajo esta ley. 
El líder de la Coordinadora Arauco Malleco (CAM), Héctor Llaitul, tampoco se quedó atrás luego de la condena de Daniel Canío. El 10 de enero, el werken de la CAM realizó un llamado que marcaría los meses venideros, incitando al Pueblo Mapuche a levantarse tanto política como militarmente en contra de las forestales, e indicando que ante la condena de Canío, "la respuesta venía". Luego de los dichos del vocero, el gobierno invocó la Ley de Seguridad del Estado en contra de este por "incitar y promover la violencia". Finalmente, el Tribunal Oral en Lo Penal de Temuco sentenció a Daniel Canío Tralcal a 16 años y seis meses de prisión. El veredicto fue confirmado el 20 de enero por la Corte Suprema luego de un recurso de nulidad presentado por el abogado de la Defensoría Popular, Rodrigo Román, quien luego de la decisión no descartó recurrir a instancias internacionales.

Sin embargo, y pese a la relevancia que tendrían estos acontecimientos en los días y meses venideros, ni los dichos de Llaitul ni la condena de Tralcal lograron generar suficiente "ruido" en redes sociales. Durante el mes de enero solo hubo 229 publicaciones originales que mencionan a Daniel Canío Tralcal o a Héctor Llaitul en Twitter, de las cuales 121 provienen de portales de noticias. Pero las repercusiones de la condena no demoraron en aparecer en el territorio. Entre el 18 y el 23 de enero se produjeron dos atentados: en el primero, se quemaron ocho equipos forestales en un predio ubicado en Lumaco y se encontró un escrito de la CAM pidiendo la libertad de Daniel Canio Tralcal. Cinco días después de este hecho, la Coordinadora se adjudicó seis ataques incendiarios y llamó a las comunidades a conformar una alianza militar. Para contrastar las menciones de estos atentados, en el mismo mes de enero se registró un total de 706 menciones originales respecto a estos ataques incendiarios, 119 de las cuales provienen de prensa en Twitter. 
Luego de lo ocurrido con Canio Tralcal, enero y febrero se convertirán en meses marcados por los diversos ataques cruzados entre el gobierno y las comunidades mapuche. Pese al crítico momento que se estaba desarrollando en La Araucanía, el 24 de febrero llegaron buenas noticias para el Pueblo Mapuche cuando el miembro de la Comunidad Autónoma de Temucuicui, José Queipul Hueiquil, fue absuelto de todos los cargos tras ser acusado de cometer cuatro delitos relacionados con armas de fuego. En el hecho sucedió en abril de 2019, el comunero fue herido por parte del personal policial que se encontraba en el lugar. Después de pasar 10 meses en prisión preventiva, las pruebas presentadas por Carabineros no fueron suficientes para acreditar el porte de armas, por lo que Tribunal de Juicio Oral en lo Penal de Angol decidió dejarlo en libertad.

La liberación del comunero mapuche sería el hecho más discutido en Twitter durante febrero. 2.050 personas compartieron la nota de BíoBío donde se menciona esta situación, la cual tuvo un alcance de poco más de tres millones de personas. Además, sólo entre el 24 y el 25 de febrero hubo un total de 4.965 publicaciones alusivas a Queipul, 29 de ellas pertenecientes a medios de prensa en internet o Twitter y cuyo alcance combinado fue de más de 5 millones de usuarios. Esta cifra es significativa, ya que durante esos dos días se registraron 13.612 menciones en Twitter, por lo que la absolución de Jose Queipul compone un $36,4 \%$ del total de menciones registradas por nuestra query durante esos días en la red social. 
Sin embargo, en prensa este hecho no tuvo la misma relevancia, ya que las 29 publicaciones respecto a Queipul corresponden solo a un 12,6\% de las publicaciones en medios de comunicación en esos días. Cabe destacar que los únicos medios tradicionales que hablaron acerca de este hecho fueron Chilevisión, CNN Chile y Bío-Bío. A finales de febrero, un hecho que marcaría la agenda varias veces en el primer semestre del año daba su puntapié inicial: la huelga de hambre del machi Celestino Córdova, iniciada el 27 de febrero en la cárcel de Temuco. Dentro de las principales peticiones que el guía espiritual demandaba, se encontraba el traslado de los internos mapuche a un módulo especial para pueblos originarios.

El 5 de marzo y luego de dos suspensiones, la atención se centró en la reanudación del juicio oral por el caso Catrillanca, pero el 20 de marzo se volvería a postergar debido a un nuevo acontecimiento que se sumaba a toda la tensión que se generaba en el Wallmapu: la pandemia por Covid-19.

\section{Asesinato de Alejandro Treuquil y huelga de hambre del ma- chi Celestino Córdova: el conflicto se recrudece}

En abril y en medio de la pandemia, los enfrentamientos entre comunidades mapuche y el gobierno se intensificaron. A esto se le sumó la nula acción por parte del Estado respecto al petitorio que los presos políticos mapuche, destacado allí el machi Celestino Córdova, habían realizado en los meses anteriores. 
Es en este contexto que el 14 de abril, la Resistencia Mapuche Lavkenche se adjudicó un ataque realizado el día anterior en el puente LleuLleu, ubicado en Tirúa. La acción se llevó a cabo mediante un auto bomba, y también incluyó personas que portaron armas de fuego para atacar al personal policial que acudió al lugar. Luego del suceso, el grupo emitió un comunicado en el cual expresaron que la institucionalidad, que ellos denominan winka, y las empresas forestales estaban amenazando con desatar una "verdadera guerra interna amparada por el gobierno, fiscales y policías". Luego de la sucesión de atentados, la agrupación Paz y Diálogo Bío Bío en conjunto con Paz en Lleu-Lleu, enviaron una carta abierta a Sebastián Piñera solicitando aplicar Estado de Emergencia en las zonas de Cañete, Contulmo y Tirúa.

En medio de la tensión que se estaba generando debido a los diferentes ataques, un nuevo hecho hizo que el descontento en las comunidades mapuche aumentara: el 17 de abril, la Corte de Apelaciones de Temuco cambió la medida cautelar de prisión preventiva a la de arresto domiciliario para el ex sargento del GOPE e imputado por el homicidio de Camilo Catrillanca, Carlos Alarcón. Esta decisión fue tomada sólo días después de que saliera a la luz que el exfuncionario policial, quien fue dado de baja en el 2018, estaba recibiendo una pensión de 900 mil pesos de parte de Carabineros de Chile. Ésta sería la historia que en Twitter se llevaría la mayor cantidad de menciones durante el mes de abril. El día 9 de ese mes, fecha en que La Tercera publicó la pensión que estaba recibiendo el ex GOPE, se registró un volumen de conversaciones en torno al tema mapuche $229 \%$ mayor que la media del mes. La nota fue compartida 2.501 veces, y otra que publicó El Desconcierto fue retuiteada 1.129 veces. Por otro lado, el 17 de abril sería el día con el tercer mayor número de menciones (174\% sobre la media), impulsado principalmente por la revocación de la prisión preventiva de Alarcón. 
El 5 de mayo y luego de varios atentados ocurridos en La Araucanía en apoyo a los presos políticos mapuche, el machi Celestino Córdova retomó la huelga de hambre en la cárcel de Temuco, la cual había suspendido en marzo por el inicio de la pandemia. La principal demanda del guía espiritual consistía en exigir el cambio de cumplimiento de condena en su comunidad junto a su Rewe. Este hecho se da justo al día siguiente del peak de menciones de mayo, que fue el día 4, donde se difundieron diversos videos y publicaciones que denunciaban una violenta represión policial en Temuco en contra de hortaliceras mapuche. 2.880 menciones utilizaron la etiqueta \#Temuco ese día, y hubo además dos videos de la represión difundidos por el medio digital Piensa Prensa, con 3.432 y 2.278 retweets cada uno, los cuales también lograron un alcance de 1.299.777 y 949.540 personas, respectivamente.

Por su parte, los comuneros Sergio Levinao, Juan Calbucoi, Víctor Llanquileo, Juan Queipul, Senecio Huenchullán, Freddy Marileo, Danilo Nahuelpi y Reinaldo Penchule, encerrados en la cárcel de Angol, también comenzaron una movilización, ya que reclamaban que Gendarmería no había tomado las medidas de higiene en el lugar para evitar los contagios de Covid-19. Además, exigían que se respetara el Convenio 169 que habla sobre el encarcelamiento y los derechos indígenas. 
En medio del clima que se estaba generando por las huelgas, otro hecho impactante volvió a remecer al Pueblo Mapuche. La madrugada del 5 de junio el werken de la comunidad We Newen, Alejandro Treuquil, fue asesinado por un impacto de bala en su cuello. La primera teoría que se barajó por parte de la Fiscalía y la Policía de Investigaciones (PDI) fue que el hecho se había dado en un contexto de robo de caballos. Dos semanas antes de que sucediera la muerte de Treuquil, el vocero de la comunidad había dado una entrevista a la Radio Universidad de Chile denunciando que estaba siendo hostigado por Carabineros. La viuda del werken, Andrea Neculpan, acusó que un par de semanas atrás su esposo había recibido un perdigón en la cabeza y que incluso lo llamaban por teléfono para amenazarlo.

Este hecho sería el segundo hito que más menciones generaría en Twitter a lo largo de todo el año. Solo el 6 de junio se generaron 99.804 menciones en la red social por parte 31.218 autores originales, lo que significó un incremento de $1.290 \%$ por sobre la media de ese mes. La etiqueta \#JusticiaparaAlejandroTreuquil fue utilizado 31.560 veces y \#WallmapuLibre otras 8.317 veces más. La palabra "Treuquil" fue la más utilizada a lo largo de todo junio, acumulando 50.968 menciones. Al analizar la nube de frases que se genera al revisar este periodo, se puede evidenciar que al centro se encuentra "George Floyd", afroamericano que se convirtió en el símbolo de la lucha contra la discriminación racista en Estados Unidos. De esto se desprende que se buscaba interpelar a la sociedad sobre el hecho de que lo ocurrido con Treuquil era muy similar a la situación de Floyd en Norteamérica. 


\section{Figura 1}

Nube de frases: \#JusticiaparaAlejandroTreuquil

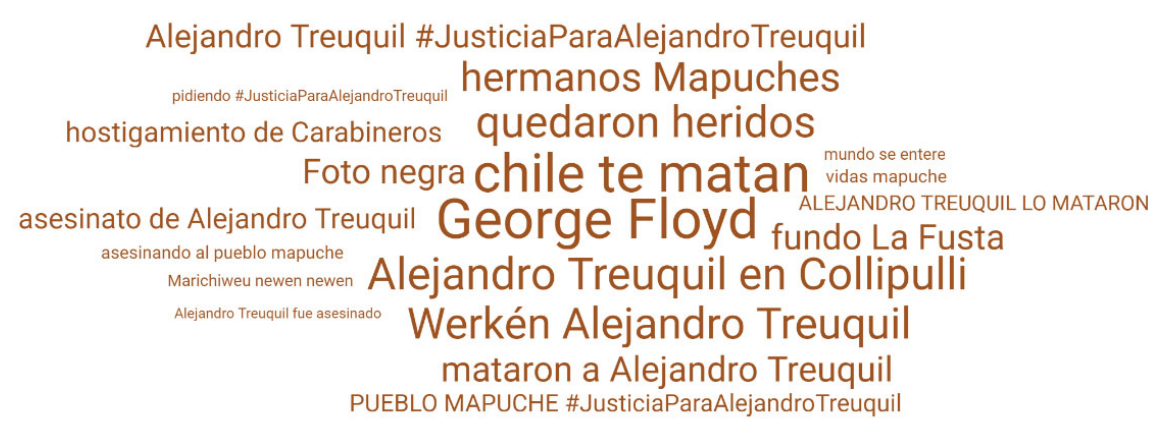

El primer semestre estaba llegando a su fin, y julio no estuvo exento de problemáticas y tensiones que desencadenarían nuevos hechos de violencia que irían en escalada. Las protestas a favor del machi Celestino Córdova fueron intensificándose, y junto a ellas, también la perseverancia y radicalización de las medidas adoptadas por la autoridad espiritual. Tras haber sido trasladado a un hospital por problemas de salud luego de 73 días sin ingerir alimentos, el machi anunció que comenzaría una huelga de hambre seca en los próximos días.

Al ver que el Gobierno seguía haciendo oídos sordos a las peticiones de los presos políticos mapuche, las municipalidades de Victoria, Collipulli, Galvarino y Angol fueron tomadas por organizaciones indígenas. Los comuneros exigían la libertad de sus compañeros encarcelados, quienes ya se encontraban bastante debilitados físicamente por las huelgas que estaban llevando a cabo. En un clima completamente polarizado, gremios de camioneros comenzaron a presionar al gobierno, amenazando con huelgas si es que su seguridad no se veía resguardada ante la escalada de violencia que decían estar sufriendo. Es, en el punto más álgido del año, que Sebastián Piñera decide nombrar a un nuevo ministro del Interior: Víctor Pérez Varela. 


\section{La errada apuesta del gobierno por Víctor Pérez}

La llegada del nuevo ministro del Interior, Víctor Pérez, fue desde un principio un tanto caótica y polémica. En primer lugar, por su pasado ligado a la dictadura militar de Pinochet, y segundo por sus dichos y acciones inmediatas en La Araucanía. A una semana de asumir el cargo, Pérez viajó a La Araucanía luego de que se reportara un "atentado incendiario" a un radar de la Dirección de Aeronáutica Civil (DGAC), la quema por parte de desconocidos de doce máquinas dedicadas a faenas forestales y de dos camiones. En este mismo contexto fue que la Corte de Apelaciones de Temuco rechazó el recurso de amparo en favor de Celestino Córdova, el que tenía como objetivo cambiar la pena que cumplía privado de libertad por la de reclusión domiciliaria hasta el término de la pandemia. Cabe destacar que el machi había depuesto la huelga de hambre seca hacía solo unos días, luego de recibir una visita del subsecretario de Justicia, Sebastián Valenzuela, y del director nacional de Gendarmería, Christian Alveal.

El clima que esperaba a Víctor Pérez el 31 de julio en La Araucanía era de total hostilidad por parte de las comunidades mapuche, quienes no tardaron en manifestarse en su contra al saber que visitaría la región. Alrededor de 150 comuneros se reunieron fuera de la Intendencia, impidiendo que Pérez pudiera ingresar al edificio en donde sostendría una reunión con el subsecretario de su misma cartera, Juan Francisco Galli. Esa misma noche y en horario de toque de queda, más de cien personas, amparadas por organizaciones anti mapuche y Carabineros, llegaron a la Municipalidad de Curacautín con el objetivo de desalojar a los comuneros que ocupaban el lugar desde hacía unos días. En un total descontrol, la turba de civiles acudió con palos y con consignas racistas al lugar. Posteriormente, lo mismo ocurrió en Victoria, replicándose lo sucedido en Curacautín. 
El resultado de los desalojos fue instantáneo, pues videos de comuneros no tardaron en llegar a las redes sociales, mostrándolos heridos por los golpes recibidos y encerrados en autos policiales. Estos hechos no sirvieron más que para reforzar y dejar en evidencia que el racismo contra la comunidad mapuche existe, y que, además, el diálogo entre el gobierno y el Pueblo Mapuche es prácticamente nulo.

Lo anterior ya había quedado evidenciado anteriormente, cuando un Relator Especial de la Organización de las Naciones Unidas (ONU) destacó que la responsabilidad de atender las demandas mapuches corresponde directamente al Estado: "Desde el restablecimiento de la democracia, ningún Gobierno, con independencia de su tendencia política, ha asignado a este tema la prioridad que merece (...) el Estado chileno tiene el deber de impulsar una solución paćfica y justa de la cuestión mapuche". (Naciones Unidas, Asamblea General, 2014, p. 8).

La noche siguiente al desalojo en Victoria y Curacautín fue una de las más críticas en todo el año, luego de que las municipalidades de Ercilla y Traiguén fueran quemadas. Entre otros dirigentes y activistas mapuches, el vocero del Consejo de Todas las Tierras, Aucán Huilcamán, responsabilizó a Víctor Pérez por los actos racistas y la violencia presenciada en la zona desde su llegada. El líder mapuche expresó que con las declaraciones del ministro este "vino a incentivar no solo la violencia institucional del Estado chileno, sino que la violencia y odiosidades raciales". 
La situación anteriormente descrita se puede explicar a través del libro Historia del Pueblo Mapuche, en donde luego de hacer una radiografía sobre el conflicto en el Wallmapu a lo largo de los siglos XIX y XX, el autor señala que "la usurpación de tierras y violencia que ejerce la sociedad chilena provoca el surgimiento, fortalecimiento y afirmación de una cultura de resistencia. Es una cultura en que la identidad colectiva está fuertemente marcada por la segregación”. (Bengoa, 1996, p. 382)

Esos días fueron sin lugar a duda el punto más álgido del año en redes sociales. Solo el 2 de agosto se registró un total de 427.591 menciones respecto al tema mapuche, es decir un $11,9 \%$ del total de menciones del año. Quienes se mostraron a favor del desalojo de los municipios difundieron los hashtags \#araucaníadespertó y \#noesracismoesterrorismo, 47.805 y 26.299 veces respectivamente. Por otro lado, entre quienes criticaron el actuar de la turba que desalojó los municipios, se difundieron los hashtags \#wallmapulibre y \#facismoenelwallmapu, 37.645 y 34.492 veces correspondientemente.

\section{Figura 2}

Nube de frases: \#araucaniadespertó y nube de frases \#wallmapulibre, \#facismoenelwallmapu

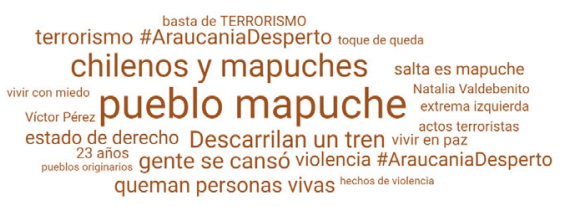


Este hecho continuaría siendo tema de debate a lo largo de todo agosto. Ese mes tuvo un promedio de menciones de $948 \%$ por sobre la media del resto de los meses del año, llegando a un total de 1.555.318 publicaciones en Twitter. Esto corresponde a 43,9\% del total del año e incluso superó los registros de noviembre de 2018, fecha en que fue asesinado Camilo Catrillanca y donde hubo un total de 1.044 .899 menciones.

Para seguir sumando tensión a la situación, el 27 de agosto y luego de varios ultimátum al gobierno de Sebastián Piñera, los camioneros, coordinados por la Confederación Nacional de Transporte de Carga, iniciaron un paro nacional en pleno peak de la pandemia del Coronavirus. La situación fue fuertemente criticada por la ciudadanía, pues el Covid-19 se encontraba en pleno apogeo, y el desabastecimiento de supermercados y servicentros, en este contexto, era muy delicado.

La movilización fue fuertemente criticada por varias razones, entre las que se encuentran una fiesta con mujeres en plena carretera y en horario de toque de queda; el bloqueo de las carreteras, y, como fue anteriormente nombrado, el desabastecimiento de las ciudades en cuanto a alimentos y combustible. En un tiempo récord, el gobierno se demoró solo una semana en dar una respuesta satisfactoria para el gremio. El ejecutivo se comprometió a invertir alrededor de 7 mil millones de pesos en infraestructura policial para resguardar la seguridad de los camioneros, además financiar programas de apoyo e indemnizaciones para los trabajadores afectados por ataques.

\section{Figura 3}

B ANUARI DEL CONFLICTE SOCIAL ... 
Nube de frases sobre camioneros, categorizadas como "en contra" del Pueblo Mapuche

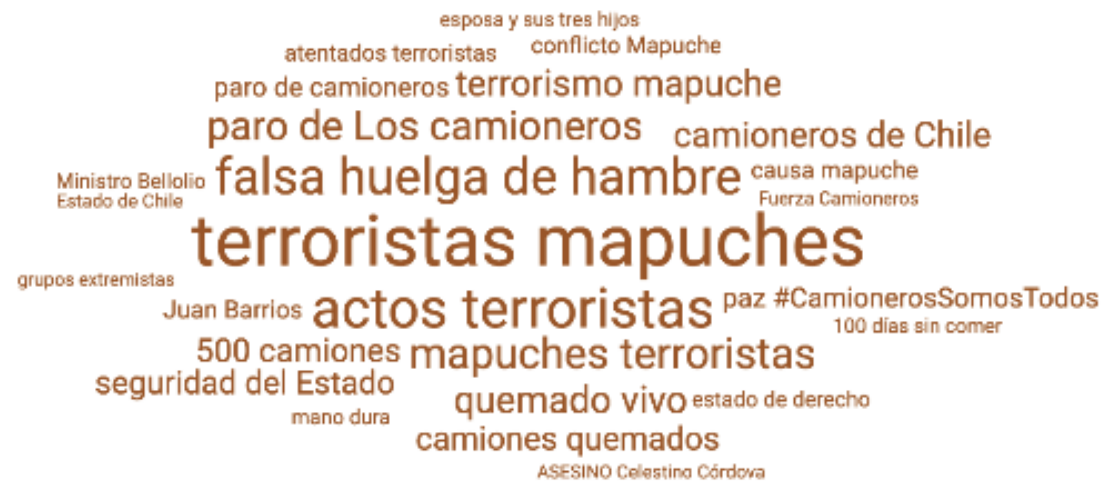

De las 83.958 menciones a los camioneros que se capturaron con la query realizada, 69.908 se producen entre el 10 de agosto y el 4 de septiembre. Esto indica que un $83,2 \%$ de las menciones hacia el gremio fueron en el contexto del paro y las movilizaciones que ellos realizaron, de las cuales una mayoría acusaba un trato injusto por parte del gobierno hacia las demandas del machi Celestino Córdova, en comparación a la celeridad con la que el ejecutivo respondió a los gremios de camioneros tras el paro. 
Siguiendo con la tónica del año, el 10 de octubre la werken de la comunidad Ad Mapu, Ana Llao, denunció un montaje que involucraba una quema de camiones y manifestó que este hecho fue para favorecer a las empresas forestales. La comunidad de Temucuicui fue acusada del atentado luego de un allanamiento hecho por la PDI, y tras negarlo, denunciaron que el gobierno una vez más era partícipe de un montaje. Sin embargo, el punto de mayor tensión del mes sucedería el 30 de octubre. Ese día se llevó a cabo un operativo policial con el objetivo de desalojar a todas las personas que se encontraran en el predio Quinta Ritz, en la comuna de Padre de las Casas. En medio del procedimiento, un grupo de desconocidos comenzó a interrumpir el tránsito quemando neumáticos, razón por la cual un carro policial se acercó al lugar. En ese contexto confuso el cabo segundo de Carabineros, Eugenio Sebastián Nain Caniumil fue herido de bala y asesinado.

Las críticas hacia la comunidad mapuche no se hicieron esperar en el mundo virtual, donde el mismo día del asesinato del cabo Nain se realizaron 1.759 publicaciones utilizando la etiqueta \#justiciaparaEugenioNain y otras 1748 con la etiqueta \#nomásimpunidad. Los dos mensajes más compartidos ese día fueron realizados por el líder del Partido Republicano, José Antonio Kast, consiguiendo 4.209 retweets combinando ambas publicaciones, y logrando un alcance de 1.086 .834 personas con la que más se difundió de las dos. 


\section{Figura 4}

Nube de frases \#justiciaparaEugenioNain y \#Nomasimpunidad

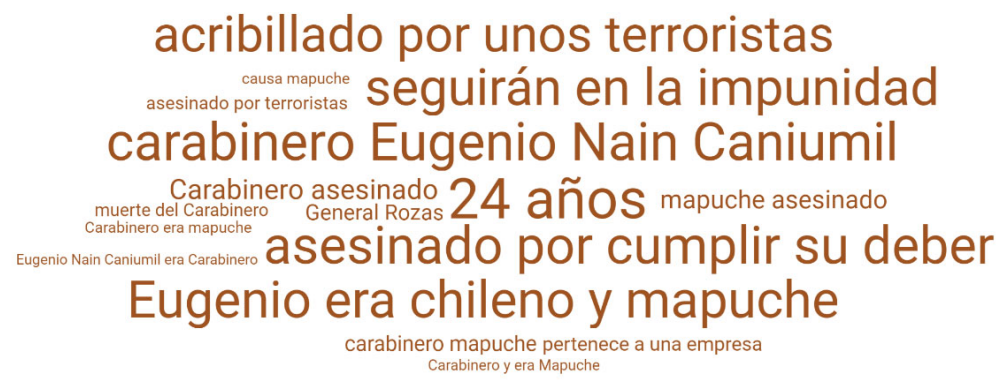

El gobierno no tardó en vincular el asesinato del joven carabinero a la causa mapuche, mientras que la familia de Nain apuntaba a todo lo contrario. El tío de Eugenio declaró ante la prensa que no contaban con el apoyo de Carabineros, y además afirmó que el hecho no tenía nada que ver con el Pueblo Mapuche.

Finalmente, y tras 98 días siendo ministro del Interior, el 3 de noviembre Víctor Pérez renunció a la cartera después de que la Cámara de Diputados aprobara una acusación constitucional en su contra. Luego de dejar su labor, Pérez afirmó que la medida tomada por la Cámara Baja había sido un ataque para obstaculizar la acción del gobierno.

\section{Caso Catrillanca: la justicia en espera por la Pandemia}


La salida de Víctor Pérez pareció poner paños fríos al conflicto entre el gobierno y el Pueblo Mapuche. Sin embargo, la conmemoración del asesinato de Camilo Catrillanca el 14 de noviembre volvió a poner en tensión la problemática. Ese día hubo un llamado a movilizarse en varias regiones del país, y específicamente en Ercilla se llevó a cabo una marcha que cortó la Ruta 5 Sur. Las cifras de Twitter demuestran que la figura de Catrillanca sigue muy presente dentro de las discusiones en torno al tema mapuche. El volumen del 14 de noviembre estuvo un $327 \%$ por sobre la media de ese mes, y 3.665 publicaciones utilizaron la etiqueta \#CamiloCatrillanca, el cual fue además el más usado durante todo el mes (4.305 veces). Finalmente, después de varias suspensiones por el Estallido Social y por la pandemia de Coronavirus, el juicio por el asesinato de Camilo Catrillanca comenzó a avanzar, luego de más de dos años de su muerte.

Este largo proceso ha ido acompañado de varias polémicas y desencuentros que ha tenido la familia de Camilo con el gobierno, el Poder Judicial, el asesino del comunero y otras autoridades gubernamentales. El 2 de diciembre fue una fecha importante en este sentido, pues ese día el imputado por el homicidio del comunero, Carlos Alarcón, hizo una declaración en la cual afirmó que altos mandos en Carabineros le instruyeron mentir en su testimonio. Ese día se registraron 23.309 menciones en Twitter, lo que equivale a un incremento de un $785 \%$ por sobre la media de ese mes. 9.908 de esas menciones (42,5\% del total del día) hicieron alusión a las declaraciones del ex GOPE, ratificando la relevancia que tiene todo lo que esté ligado al caso Catrillanca. 
Mientras Alarcón declaraba en el juicio oral ese día, el padre de Camilo, Marcelo Catrillanca, denunciaba que no lo dejaban salir de su comunidad en Temucuicui por un proceso policial que se estaba llevando a cabo en el sector, el cual incluía vehículos blindados. Debido a la situación, la familia del joven mapuche asesinado llegó tarde al Tribunal de Angol. Si se observa la data a lo largo de todo el año, los números son aún más sorprendentes. 345.336 publicaciones en Twitter mencionaron a Catrillanca a lo largo de todo el año, lo que representa un $9,6 \%$ del total de las menciones. Que a dos años de su asesinato, la figura del comunero siga teniendo tanta relevancia, demuestra que el impacto generado por su muerte seguirá teniendo consecuencias en las discusiones futuras respectos al tema mapuche.

\section{Escaños reservados y la esperanza de una nueva Constitución}

Pese a las tensiones que aún se albergaban en el Wallmapu, el triunfo del Apruebo en el plebiscito por una nueva Constitución reanudó complejas negociaciones por los escaños reservados. Noviembre y diciembre fueron meses claves en la discusión sobre la inclusión de los pueblos indígenas en el proceso constituyente. Uno de los principales puntos que demoró en llegar a acuerdo fue la cantidad de cupos que se les otorgaría a los pueblos originarios: la propuesta de oposición consistía en una cuota de 24 , pero el oficialismo se negaba a otorgar esta cantidad. A esto se le sumó la problemática que surgió en medio de la discusión por este proyecto de si el quórum de votación para reservar los cupos a los representantes de pueblos indígenas sería de tres quintos o de dos tercios. En resumen, el Senado decidió por 22 votos contra 18 que el quórum se mantendría en tres quintos. 
En medio de toda la discusión por la reforma sobre los escaños reservados, una destacada figura mapuche femenina alzaría su voz: la machi Francisca Linconao, quien fue perseguida policial y judicialmente en el contexto del caso Luchsinger-Mackay. Luego de varias especulaciones, la líder espiritual decidió confirmar su candidatura como constituyente. Pero Linconao no sería la única que tomaría esta decisión: también se le sumarían la presidenta del Centro de Investigación y Defensa Sur, Natividad Llanquileo; la dirigenta de la comunidad Ad Mapu, Ana Llao; la impulsora de los derechos educativos y lingüísticos de los pueblos indígenas, Elisa Loncón, entre otras personas.

Luego de incongruencias, desacuerdos, discusiones y múltiples cambios al proyecto, el 15 de diciembre el Senado aprobó 17 escaños reservados para pueblos originarios, de los cuales siete corresponden al Pueblo Mapuche. Finalmente, el 23 de diciembre Sebastián Piñera promulgó la reforma. La inclusión de los escaños reservados para la Convención Constituyente había sido un tema discutido y postergado durante todo el año, acumulando un total de 16.085 menciones. Los días posteriores al triunfo del Apruebo y Convención Constitucional en el plebiscito comenzaron a posicionarse los hashtags a favor de los cupos, como \#escañosreservadosya y \#escañosreservadosindígenas, que consiguieron 1.293 y 895 menciones cada uno, lo que conforma un $13,6 \%$ del total de las menciones acerca de los escaños. 


\section{Figura 5}

Nube de frases: \#escañosreservadosya y \#escañosreservadosindigenas

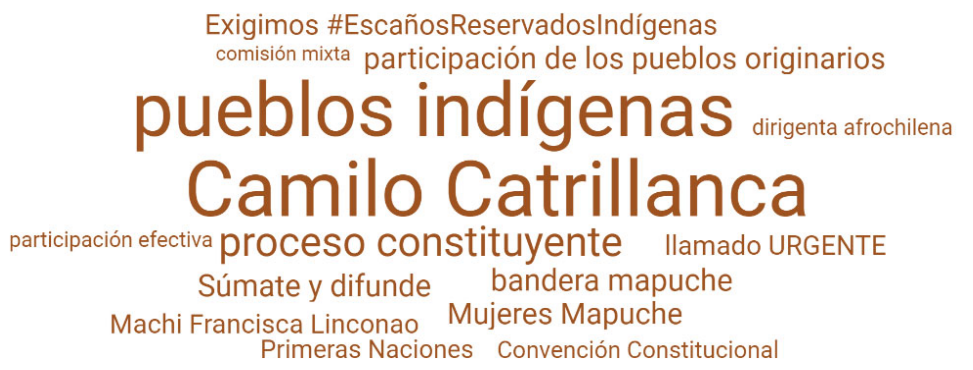

Este impulso en las menciones de escaños reservados que se da una vez terminada la votación en el plebiscito puede pasar como algo anecdótico, pero es la primera muestra de cómo la ciudadanía puede ser capaz de involucrarse e influenciar las decisiones que se tomen a lo largo de todo el proceso constituyente de aquí en adelante.

\section{Reflexiones finales}

El conflicto que existe actualmente entre el Estado chileno y el Pueblo Mapuche es muy complejo; en parte porque abarca un período de tiempo muy largo, y además, los matices que existen dentro de esta problemática son muchos a lo largo de la historia. En este sentido, en el libro “...Escucha, winka...!" se destaca que "los indígenas, como sociedades colonizadas, fueron integrados a la fuerza a las estructuras sociales y productivas de los Estados nacionales, estructuras que fueron suprimiendo, a veces de forma violenta y definitiva, sus formas socioculturales originales”. (Caniqueo, Levil, Marimán y Millalén, 2006, p. 246). 
La lucha constante entre los gobiernos y las comunidades es algo que se está evidenciando desde hace años. Es por esto que es de gran importancia observar este tema de forma cronológica, pues las acciones que se han perpetrado a lo largo del tiempo, que incluyen ataques, quemas, protestas y movilizaciones, no son aleatorias ni azarosas: son acciones pensadas con un fin político y una concatenación de interacciones.

En este mismo sentido, las situaciones que se vivieron en el 2020, entre las que están tomas de municipios y de terrenos, e incluso huelgas de hambre que pudieron llevar a la muerte a quienes las llevaron a cabo, se enmarcan en un contexto claro: el gobierno haciendo oídos sordos a las peticiones que hace años viene demandando el Pueblo Mapuche, y, que, en vez de escuchar, prefiere reprimir aplicando leyes discriminatorias y punitivas. Hoy, la Ley Antiterrorista se utiliza con el fin de criminalizar a grupos de resistencia. No es coincidencia que muchos organismos internacionales cuestionen el uso de este recurso. Primero, por la deficiente definición que existe sobre lo que es un acto terrorista; segundo, debido a los métodos especiales que se utilizan para investigar, como lo son los testigos protegidos, y finalmente por su uso discriminatorio contra un pueblo indígena, incumpliendo criterios mínimos del debido proceso. 
Si las medidas del gobierno y del oficialismo ya han sido nulas en el plano legislativo, desde lo que se pudo apreciar en la narrativa de internet y redes sociales el panorama no cambia mucho, pues tampoco se encontró alguna acción o medida por parte del ejecutivo para mejorar la relación con el Pueblo Mapuche y los adherentes a su causa política. De hecho, todo lo contrario: el oficialismo no ha hecho más que entorpecer procesos que podrían ser fructíferos para la resolución del conflicto. Lo último pudo ser apreciado en la discusión sobre los escaños reservados, ya que cada jornada de discusión en la Cámara de Diputados significó un entorpecimiento al proceso y una constante negativa a la hora de incluir en el proceso constituyente a los pueblos indígenas que se encuentran en Chile. Sin embargo, y a pesar de todos estos obstáculos que se han presentado en el año, la fuerza y la perseverancia que el Pueblo Mapuche demuestra en sus tierras y en su lucha también se puede ver reflejada en las redes sociales. Esto es lo que sucede, por ejemplo, con el weichafe asesinado a manos de Carabineros, Camilo Catrillanca. Su imagen aún prevalece no solamente en las comunidades, sino que también en la mente de los chilenos, quienes en gran cuantía se han manifestado fuertemente a través de las plataformas digitales en contra de las injusticias y atropellos hacia el Pueblo Mapuche.

La escucha social se ha convertido en una gran herramienta para monitorear qué es lo que se está hablando de ciertos temas, y el conflicto entre el Estado de Chile y el Pueblo Mapuche no ha sido ni será la excepción. Si bien es un mundo virtual, cada vez se está configurando más como un nuevo espacio público en el que las discusiones se van desarrollando y profundizando y que, además, puede llegar a influenciar significativamente la agenda política y de los medios de comunicación. 


\section{Anexos}

\begin{tabular}{|l|l|l|}
\hline Fecha & Acontecimiento & Descripción \\
\hline $\begin{array}{l}\text { enero, } \\
2020\end{array}$ & $\begin{array}{l}\text { Tribunal Oral en Lo } \\
\text { Aenal de Temuco } \\
\text { comunero Daniel } \\
\text { Canío Tralcal. }\end{array}$ & $\begin{array}{l}\text { El comunero mapuche Daniel } \\
\text { Canío Tralcal fue declarado } \\
\text { culpable por diversos delitos } \\
\text { ocurridos dos años antes en } \\
\text { un fundo propiedad de la Fo- } \\
\text { restal Arauco. }\end{array}$ \\
\hline $\begin{array}{l}24 \text { de fe- } \\
\text { brero, }\end{array}$ & $\begin{array}{l}\text { José Queipul es ab- } \\
\text { suelto de todos los } \\
\text { cargos que le impu- } \\
\text { taban. }\end{array}$ & $\begin{array}{l}\text { El miembro de la comunidad } \\
\text { autónoma Temucuicui fue ab- } \\
\text { suelto de cuatro delitos con } \\
\text { armas de fuego que le eran } \\
\text { imputados. }\end{array}$ \\
\hline $\begin{array}{l}\text { 27 de fe- } \\
\text { brero, }\end{array}$ & $\begin{array}{l}\text { Machi Celestino } \\
\text { Córdova inicia huel- } \\
\text { ga de hambre. }\end{array}$ & $\begin{array}{l}\text { El Machi Celestino Córdova } \\
\text { inicia una huelga de hambre } \\
\text { en la cárcel de Temuco, solici- } \\
\text { tando el traslado de presos } \\
\text { mapuche a un módulo especial } \\
\text { para pueblos originarios. }\end{array}$ \\
\hline $\begin{array}{l}\text { to de agos- } \\
\text { nio, 2020 } 2020\end{array}$ & $\begin{array}{l}\text { Carabineros y civiles } \\
\text { desalojan municipa- } \\
\text { lidades de Victoria y }\end{array}$ & $\begin{array}{l}\text { Carabineros y grupos de civi- } \\
\text { les amparados por organiza- } \\
\text { ciones anti mapuches acuden }\end{array}$ \\
\hline $\begin{array}{l}\text { Alejandro Treuquil, werkén de } \\
\text { la comunidad We Newen es } \\
\text { asesinado por un impacto de } \\
\text { bala en su cuello, semanas } \\
\text { después de haber denunciado } \\
\text { que estaba siendo hostigado } \\
\text { por carabineros. }\end{array}$ \\
\hline
\end{tabular}




\begin{tabular}{|l|l|l|}
\hline & Curacautín & $\begin{array}{l}\text { con palos y desalojan por la } \\
\text { fuerza las municipalidades de } \\
\text { Victoria y Curacautín, que se } \\
\text { encontraban tomadas por ma- } \\
\text { puches. }\end{array}$ \\
\hline $\begin{array}{l}27 \text { de } \\
\text { agosto }\end{array}$ & $\begin{array}{l}\text { Camioneros inician } \\
\text { un paro nacional }\end{array}$ & $\begin{array}{l}\text { La Confederación Nacional de } \\
\text { Transporte de Carga inicia un } \\
\text { paro nacional en pleno peak } \\
\text { de la pandemia, denunciando } \\
\text { el abandono del gobierno ante } \\
\text { los ataques en contra de sus } \\
\text { máquinas. }\end{array}$ \\
\hline 30 de oc- & $\begin{array}{l}\text { Asesinato del cabo } \\
\text { Eugenio Nain }\end{array}$ & $\begin{array}{l}\text { El cabo segundo de carabine- } \\
\text { ros, Eugenio Nain es asesina- } \\
\text { do en medio de un procedi- } \\
\text { miento policial en contra de } \\
\text { un grupo de desconocidos que } \\
\text { quemaban neumáticos en la } \\
\text { Comuna de Padre las Casas. }\end{array}$ \\
\hline $\begin{array}{l}\text { Cug de di- } \\
\text { ciembre }\end{array}$ & $\begin{array}{l}\text { Se promulga la re- } \\
\text { forma que establece } \\
\text { escaños reservados } \\
\text { narios }\end{array}$ & $\begin{array}{l}\text { Luego de meses de discusio- } \\
\text { nes y desacuerdos, el Senado } \\
\text { aprobó 17 escaños reservados } \\
\text { para pueblos originarios, de } \\
\text { los cuales siete corresponden } \\
\text { al pueblo mapuche, reforma } \\
\text { que fue promulgada el 23 de } \\
\text { diciembre por el presidente } \\
\text { Sebastián Piñera. }\end{array}$ \\
\hline
\end{tabular}

B 


\section{Referencias}

Bengoa, J. (1996). Historia del Pueblo Mapuche (Siglos XIX y XX). Ediciones Sur.

Caniuqueo, S., Levil, R., Marimán, P. y Millalén, J.(2006). j...Escucha, winka...!. Lom Ediciones.

Cortés Morales, J. (2019). Legislación antiterrorista en Chile: diagnóstico y propuestas de modificación. http://www.ciir.cl/ciir.cl/wpcontent/uploads/2019/01/policy-paper-UPP-n $\%$ C2\%BA32019-.pdf

Naciones Unidas (2014). Informe del Relator Especial sobre la promoción y protección de los derechos humanos y las libertades fundamentales en la lucha contra el terorismo.

http://digitallibrary.un.org/record/767042/files/A HRC 25 59 Add.3-ES.pdf

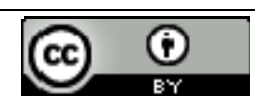

Este texto está protegido por una licencia Reconocimiento Creative Commons 4.0.

Usted es libre para Compartir — copiar y redistribuir el material en cualquier medio o formato- y Adaptar el documento — remezclar, transformar y crear a partir del material— para cualquier propósito, incluso comercialmente, siempre que cumpla la condición de:

Atribución: Usted debe reconocer el crédito de una obra de manera adecuada, proporcionar un enlace a la licencia, e indicar si se han realizado cambios. Puede hacerlo en cualquier forma razonable, pero no de forma tal que sugiera que tiene el apoyo del licenciante o lo recibe por el uso que hace. 